\title{
Pengaruh Pelatihan dan Pengalaman Kerja Terhadap Produktivitas Kerja Karyawan Pada PT. Tunas Baru Lampung, Tbk- Banyuasin
}

\author{
Aisah Nurramadhani Lubis ${ }^{1}$, Suhada $^{2}$ \\ ${ }^{1}$ Manajemen, Fakultas Ekonomi dan Bisnis UPGRI Palembang, aisahnurramadhanilubis@gmail.com \\ ${ }^{2}$ Manajemen, Fakultas Ekonomi dan Bisnis UPGRI Palembang, Suhadaahmadmadjid@gmail.com
}

\begin{abstract}
ABSTRAK
Penelitian ini bertujuan untuk mengetahui Pengaruh Pelatihan dan Pengalaman Kerja terhadap Produktivitas Kerja pada PT. Tunas Baru Lampung, Tbk-Banyuasin. Metode penelitian yang digunakan adalah metode penelitian kuantitatif, dengan populasi seluruh karyawan PT. Tunas Baru Lampung, Tbk-Banyuasin berjumlah 89 orang. Sampel yang digunakan dalam penelitian ini menggunakan teknik sampling jenuh sehingga diperoleh sampel sebanyak 72 orang karyawan. Teknik pengumpulan data dilakukan dengan observasi dan kuisioner. Teknik analisis data menggunakan regresi linier berganda, koefisien determinasi, pengujian hipotesis uji t dan uji $F$. Hasil penelitian ini dapat diketahui bahwa nilai persamaan regresi linier berganda $Y=6,844+0,166 X_{1}+0,783 X_{2}+$ e. Hasil koefisien determinasi menunjukan nilai $R$ square sebesar 0,651 atau $65,1 \%$ artinya kontribusi sumbangan pengaruh Pelatihan $\left(X_{1}\right)$ dan Pengalaman Kerja $\left(X_{2}\right)$ terhadap Produktivitas Kerja $(Y)$ sebesar $65,1 \%$. Hasil pengujian hipotesis uji t Pelatihan $\left(\mathrm{X}_{1}\right)$ terhadap Produktivitas Kerja $(\mathrm{Y})$ diperoleh nilai signifikan $0,155>$ a signifikan 0,05 maka dapat disimpulkan secara parsial tidak ada pengaruh yang signifikan antara Pelatihan terhadap Produktivitas Kerja pada PT. Tunas Baru Lampung, Tbk-Banyuasin. Hasil pengujian hipotesis uji t Pengalaman Kerja $\left(\mathrm{X}_{2}\right)$ terhadap Produktivitas Kerja diperoleh nilai signifikan $0,000<\alpha$ signifikan 0,05 maka dapat disimpulkan secara parsial ada pengaruh yang signifikan antara Pengalaman Kerja terhadap Produktivitas Kerja pada PT. Tunas Baru Lampung, Tbk-Banyuasin. Hasil pengujian hipotesis uji F diperoleh nilai signifikan $0,000<$ a 0,05 maka hipotesis $\mathrm{H}_{a}$ (Hipotesis alternatif) diterima dan $\mathrm{H}_{0}$ (Hipotesis nol) ditolak, maka dapat disimpulkan bahwa secara bersama-sama ada pengaruh yang signifikan antara Pelatihan dan Pengalaman Kerja terhadap Produktivitas Kerja pada PT. Tunas Baru Lampung, Tbk-Banyuasin.
\end{abstract}

Kata kunci : Pelatihan, Pengalaman Kerja, Produktivitas Kerja

\section{ABSTRACK}

This study aims to determine the Effect of Training and Work Experience on Work Productivity at PT. Tunas Baru Lampung, Tbk-Banyuasin. The research method used is a quantitative research method, with a population of all employees of PT. Tunas Baru Lampung, Tbk-Banyuasin numbered 89 people. The sample used in this study used a saturated sampling technique to obtain a sample of 72 employees. Data collection techniques are done by observation and questionnaire. Data analysis techniques used multiple linear regression, coefficient of determination, $t$ test hypothesis testing and $F$ test. The results of this study can be seen that the value of the multiple linear regression equation $Y=$ $6,844+0,166 X 1+0,783 X 2+e$. The results of the coefficient of determination show an $R$ square value of 0.651 or $65.1 \%$, meaning that the contribution of the contribution of training (X1) and Work Experience (X2) to Work Productivity $(Y)$ is $65.1 \%$. Hypothesis testing results of the Training t test $(X 1)$ on Work Productivity $(Y)$ obtained a significant value of $0.155>$ a significant 0.05 , it can be concluded partially there is no significant effect between Training on Work Productivity at PT. Tunas Baru Lampung, Tbk-Banyuasin. The results of testing the $t$ test hypothesis of Work Experience (X2) on Work Productivity obtained a significant value of $0,000<\alpha$ significant 0.05 , it can be concluded partially there is a significant influence between Work Experience on Work Productivity at PT. Tunas Baru Lampung, Tbk-Banyuasin. The results of testing the $F$ test hypothesis obtained a significant value of $0,000<\alpha 0.05$ then the Ha hypothesis (alternative hypothesis) is accepted and HO (null hypothesis) is rejected, it can be concluded that together there is a significant effect between Training and Work Experience on Work Productivity at PT. Tunas Baru Lampung, Tbk-Banyuasin.

Keywords: Training, Work Experience, Work Productivity

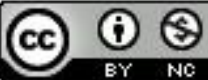




\section{A. PENDAHULUAN}

Sunyoto (2018:137) pelatihan kerja bagi perusahaan merupakan aktivitas yang cukup penting dilakukan hal ini dapat mempengaruhi tingkat produktivitas dan prestasi kerja bagi tenaga kerja itu sendiri dan organisasii perusahaan dimana tenaga kerja tersebut bekerja..

Pelatihan yang dilakukan di PT. Tunas Baru Lampung, Tbk.Banyuasin ditunjukan kepada karyawan baru dan karyawan lama. Agar kemampuan kerja karyawan dapat memadai dan meningkatkan kemampuan karyawan sehingga dapat bekerja secara optimal. Dalam pengamatan yang dilakukan peneliti ada jenis pelatihan yaitu pelatihaan training orientasi dan soft skills pelatihan ini diberikan kepada karyawan baru dan karyawan lama agar pengetahuan dan keterampilan karyawan lebih meningkat dan mempunyai keahlian lebih dibidangnya. Pelatihan untuk karyawan baru dilakukan dalam waktu 1 bulan sedangkan untuk karyawan lama pelatihan dilakukan 6 bulan sekali dan melakukan pelatihan kerja sesuai dengan bidang karyawan masingmasing.

Dengan adanya pelatihan yang cukup, karyawan memiliki kesempatan untuk menyerap pengetahuan dan nilai-nilai baru sehingga dapat mempunyai pengalaman kerja.

Dengan melihat adanya pengalaman kerja maka dapat menilai karyawan tersebut ahli dibidangnya atau tidak. Di PT. Tunas Baru Lampung, Tbk-Banyuasin banyak karyawan yang memiliki pengalaman kerja sudah cukup lama, akan tetapi skill atau keahlianya tidak seimbang dengan pengalaman kerjanya dan masih banyak karyawan yang belum memahami setiap fungsi pekerjaan. Seperti adanya karyawan yang berpengalaman kerja dibidang administrasi keuangan akan tetapi di tempatkan dibagian kabag gudang, penempatan tersebut tidak sesuai dengan pengalaman kerja yang dimiliki oleh karyawan.

Pengalaman kerja yang dimiliki oleh karyawan maka kepuasaan kerja akan lebih tinggi. Penempatan yang sesuai dengan pengalaman kerja karyawan yang baik dapat mempengaruhi kesuksesan perusahaan untuk mewujudkan suatu tujuan. Hal tersebut nantinya akan nampak pada produktivitas kerja yang diharapkan akan semakin meningkat lagi. Melalui pengalaman kerja akan menciptakan tingkat produktivitas kerja yang tinggi sehingga dapat menunjang keberhasilaan perusahaan.

\section{B. KAJIAN TEORI \\ 1) Pelatihan \\ Mangkunegara} pendidikan jangka pendek yang mempergunakan prosedur sistematis dan terorganisasi, yang mempelajari pengetahuan dan keterampilan teknis dalam meningkatkan kualitas karyawan.

\section{2) Pengalaman Kerja}

Yuniarsih dan Suwatno (2016:117) Pengalaman kerja yaitu pengalaman seseorang tenaga kerja untuk melakukan pekerjaan tertentu, pengalaman pekerjaan ini dinyatakan dalam pekerjaan yang harus dilakukan dan lamanya melakukan pekerjaan itu.

\section{3) Produktivitas Kerja}

Hasibuan (2017:94) produktivitas kerja adalah perbandingan antara output dengan input, dimana outputnya harus mempunyai nilai tambah dan teknik pengerjaanya yang lebih baik. 


\section{METODE PENELITIAN}

Pada metode penelitian Penulis menggunakan metode kuantitatif yang diartikan sebagai metode penelitian yang berlandaskan pada filsafat positivisme, digunakan untuk meneliti pada populasi atau sampel tertentu, pengumpulan data menggunakan instrument penelitian, analisis data bersifat kuantitatif statistik, dengan tujuan untuk menguji hipotesis yang telah ditetapkan.

1) Populasi

Populasi yang digunakan dalam penelitian ini ialah seluruh karyawan tetap pada PT. Tunas Baru Lampung,Tbk-Banyuasin yang berjumlah 89 orang karyawan tetap.

2) Sampel

Sampel didalam penelitian ini diambil hanya 72 orang karyawan yang telah mengikuti pelatihan Kerja pada PT. Tunas Baru Lampung, TbkBanyuasin.

3) Teknik Pengumpulan Data
Teknik pengumpulan data dalam penelitian ini adalah :

a. Kuisioner

Kuisioner merupakan teknik pengumpulan data yang dilakukan dengan cara memberikan seperangkat pertanyaan kepada orang lain yang dijadikan responden untuk dijawabnya.

b. Observasi

Observasi merupakan teknik pengumpulan data yang tidak hanya mengukur sikap dari responden namun juga digunakan untguk merekam berbagai fenomena situasi dan kondisi.

\section{HASIL PENELITIAN}

\section{Hasil Regresi Linier Berganda}

Analisis regresi linier berganda untuk mencari nilai pengaruh dua variabel bebas atu lebih terhadap variabel terikat besarnya pengaruh tersebut dapat dilihat pada tabel dibawah ini.

Tabel Hasil Analisis Regresi Linier Berganda Coefficients $^{\mathrm{a}}$

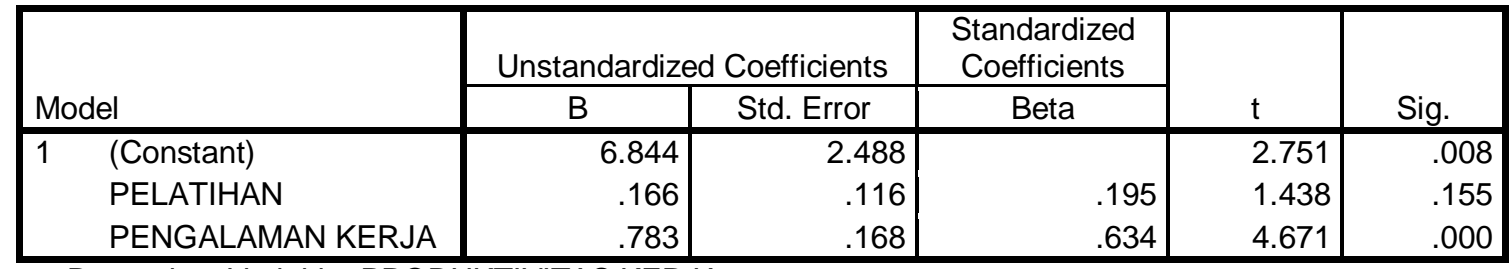

a. Dependent Variable: PRODUKTIVITAS KERJA

Sumber : pengolah data, 2020

Dari perhitungan diatas didapatkan hasil konstanta sebesar 6,844 beta variabel Pelatihan (X1) sebesar 0,166 serta beta variabel Pengalaman Kerja (X2) sebesar 0,783, maka dapat dirumuskan persamaan regresi linier berganda sebaagai berikut:

$\mathrm{Y}=\mathrm{a}+\mathrm{b}_{1} \mathrm{X}_{1}+\mathrm{b}_{2} \mathrm{X}_{2}+\mathrm{e}$

$Y=6,844+0,166 X_{1}+0,783 X_{2}+e$
Berdasarkan hasil persamaan regresi linier berganda, maka dapat dianalisis sebagai berikut:

1) Koefisien regresi Pelatihan sebesar 0,166 berarti Pelatihan kerja sebesar satu persen akan mengurangi Produktivitas Kerja sebesar $16,6 \%$.

2) Koefisien regresi Pengalaman kerja sebesar 0,783 berarti bahwa peningkatan Pengalaman Kerja 
sebesar satu persen akan meningkatkan Produktivitas Kerja sebesar $78,3 \%$.

\section{Koefisien Determinasi}

Untuk mengetahui besarnya pengaruh variabel Pelatihan dan Pengalaman kerja terhadap variabel Produktivitas Kerja dapat dilihat pada Tabel berikut :

Tabel Hasil Analisis Koefisien Determinasi

Model Summaryb

\begin{tabular}{l|r|r|r|r|}
\hline Model & $\mathrm{R}$ & $\mathrm{R}$ Square & Adjusted R Square & Std. Error of the Estimate \\
\hline 1 & $.807^{\mathrm{a}}$ & .651 & .641 & 2.600 \\
\hline
\end{tabular}
a. Predictors: (Constant), PENGALAMAN, PELATIHAN
b. Dependent Variable: PRODUKTIVITAS KERJA

\section{Sumber : Data diolah dengan program SPSS versi 23}

Koefisien determinasi digunakan
untuk mengetahui presentase
sumbangan variabel independen secara bersam-sama terhadap variabel dependen. Jika koefisien korelasi berganda dikuadratkan diperoleh koefisien penentu berganda dengan melihat nilai $R$ sequare. Berdasarkan perhitungan model summary nilai $R$ square sebesar 0,651 sehingga dalam penelitian ini Pelatihan dan Pengalaman Kerja dapat menjelaskan Produktivitas Kerja sebesar 65,1 dan 34,9 sisanya dipengaruhi oleh variabel lain yang tidak diteliti dalam penelitian ini.

\section{Pengujian Hipotesis}

Pengujian hipotesis menunjukkan seberapa jauh pengaruh satu variabel bebas secara individual dalam menerangkan variasi variabel terikat.
Pengujian hipotesis tentang pengaruh desain kerja dan lingkungan kerja terhadap kinerja pegawai dilakukan dengan uji-t dan untuk menunjukkan pengaruh variabel bebas secara bersama-sama terhadap variabel terikat melalui uji $\mathrm{F}$ dengan taraf signifikansi 0,05.

\section{Hasil Uji t}

Uji parsial (uji-t) dilakukan untuk menguji signifikansi pengaruh variabelvariabel bebas (Pelatihan dan Pengalaman kerja) secara parsial/individual terhadap variabel terikat (Produktivitas Kerja) di PT.Tunas Baru Lampung, TbkBanyuasin. Uji-t dalam penelitian ini digunakan untuk melakukan pengujian hipotesis dengan tingkat signifikansi $(\alpha=0,05)$. Uji-t ditunjukkan pada Tabel sebagai berikut:

\section{Tabel Uji-t Pelatihan $\left(\mathrm{X}_{1}\right)$ terhadap Produktivitas Kerja $(\mathrm{Y})$ Coefficients $^{\mathrm{a}}$}

\begin{tabular}{|c|c|c|c|c|c|}
\hline \multirow[b]{2}{*}{ Model } & \multicolumn{2}{|c|}{ Unstandardized Coefficients } & \multirow{2}{*}{$\begin{array}{c}\begin{array}{c}\text { Standardized } \\
\text { Coefficients }\end{array} \\
\text { Beta }\end{array}$} & \multirow[b]{2}{*}{$\mathrm{t}$} & \multirow[b]{2}{*}{ Sig. } \\
\hline & $\mathrm{B}$ & Std. Error & & & \\
\hline $1 \quad$ (Constant) & 6.844 & 2.488 & & 2.751 & .008 \\
\hline PELATIHAN & .166 & .116 & .195 & 1.438 & .155 \\
\hline PENGALAMAN KERJA & .783 & .168 & .634 & 4.671 & .000 \\
\hline
\end{tabular}

a. Dependent Variable: PRODUKTIVITAS KERJA

Sumber : Data diolah dengan Program SPSS Versi 23

Berdasarkan tabel diatas hasil menunjukkan nilai signifikan antara
Variabel Pelatihan terhadap Produktivitas Kerja sebesar 0,155 > 
0,05 artinya $\mathrm{H}_{\mathrm{o}}$ diterima dan $\mathrm{Ha}$ ditolak sehingga dapat disimpulkan bahwa tidak ada pengaruh yang signifikan antara Pelatihan terhadap Produktivitas Kerja sedangkan Pengalaman Kerja terhadap Produktivitas Kerja sebesar 0,000< 0,05 artinya $\mathrm{Ho}_{\mathrm{o}}$ ditolak dan $\mathrm{H}_{\mathrm{a}}$ diterima yang berarti ada pengaruh signifikan antara Pengalaman Kerja dan Produktivitas Kerja pada PT. Tunas Baru Lampung, Tbk-Banyuasin.

\section{Hasil Uji F}

Uji $\mathrm{F}$ digunakan untuk menjelaskan variabel bebas (Pelatihan dan Pengalaman Kerja) secara bersama-sama atau simultan berpengaruh signifikan terhadap variabel terikat (Produktivitas Kerja). Uji F ditujukan untuk mengukur tingkat keberartian hubungan secara keseluruhan koefisien regresi dari variabel bebas terhadap variabel terikat dengan menentukan nilai uji $\mathrm{F}$ dengan tabel ANOVA (analysis of variance) dan tingkat signifikans dapat dilihat table sebagai berikut:

Tabel Hasil pengujian secara simultan dengan uji -F ANOVA $^{a}$

\begin{tabular}{|cc|c|c|c|c|c|}
\hline \multicolumn{1}{|c|}{ Model } & Sum of Squares & Df & Mean Square & F & Sig. \\
\hline 1 & Regression & 870.347 & 2 & 435.174 & 64.363 & $.000^{\mathrm{b}}$ \\
& Residual & 466.528 & 69 & 6.761 & & \\
& Total & 1336.875 & 71 & & & \\
\hline
\end{tabular}

a. Dependent Variable: PRODUKTIVITAS KERJA

b. Predictors: (Constant), PENGALAMAN, PELATIHAN

Sumber : Data diolah dengan program SPSS Versi 23

Berdasarkan uji $\mathrm{F}$ pada tabel diatas menunjukan nilai signifikan sebesar $0,000<0,05$ artinya $\mathrm{H}_{\circ}$ ditolak dan $\mathrm{Ha}$ diterima. Sehingga dapat disimpulkan bahwa terdapat ada pengaruh yang signifikan Pelatihan Kerja (X1) dan Pengalaman Kerja (X2) terhadap Produktivitass Kerja (Y) pegawai pada PT. Tunas Baru Lampung, Tbk-Banyuasin.

\section{E. PEMBAHASAN}

Berdasarkan hasil uji validitas menunjukan semua item pertanyaan yang digunakan dalaam variabel pelatihan dalam penelitian ini mempunyai nilai yang signifikan 0,000 $<0,05$ dengan sampel 72 orang dari hasil tersebut maka semua item dinyatakan valid.

Dari hasil uji realibitas untuk variabel Pelatihan, Pengalaman Kerja dan Produktivitas kerja karyawan masing-masing mempunyai nilai Cronbach Alpha sebesar 0,896, 0,872 dan 0,911 . karena semua nilai tersebut > 0,60 maka dapat disimpulkan bahwa seluruh item pertanyaan reliabel.

Dari hasil persamaan regresi linier berganda diperoleh nilai konstanta sebesar 6,844, hal ini berarti jika variabel Pelatihan $\left(X_{1}\right)$ dan variabel Pengalaman Kerja $\left(X_{2}\right)$ sama dengan nol, maka Produktivitas Kerja $(Y)=6,844$. Apabila variabel Pelatihan $\left(X_{1}\right)$ meningkat sebesar 0,166 satu satuan sedangkan variabel lainya tetap, maka akan diikuti dengan peningkatan Produktivitas Kerja sebesar $\quad 0,166$ satu satuan. Sebaliknya jika Pelatihan menurun satu satuan maka Produktivitas Kerja akan mengalami penurunan sebesar 0,166 satu satuan. Apabila Pengalaman Kerja $\left(\mathrm{X}_{2}\right)$ meningkat 
sebesar 0,783 satu satuan sedangkan variabel lainya tetap, maka akan diikuti dengan peningkatan Produktivitas Kerja sebesar 0,783 satu satuan. Sebaliknya jika Pengalaman Kerja menurun sebesar satu satuan maka Produktivitas Kerja akan ikut menurun sebesar 0,783 satu satuan.

Maka dapat disimpulkan bahwa variabel Pelatihan dan Pengalaman Kerja mempengaruhi Produktivitas Kerja pada PT. Tunas Baru Lampung, Tbk-Banyuasin. Hasil analisis koefisien determinasi $R$ square $\left(R^{2}\right)$ sebesar 0,651 atau $65,1 \%$ yang berarti bahwa produktivitas kerja karyawan dapat dijelaskan oleh variabel Pelatihan dan Pengalaman Kerja sebesar (100$65,1 \%)$ Sedangkan sisanya (34,9\%) dipengaruhi oleh faktor-faktor lain yang tidak diteliti.

\section{Pengaruh Pelatihan dan \\ Pengalaman Kerja Terhadap Produktivitas Kerja Pada PT. Tunas Baru Lampung, Tbk- Banyuasin. \\ Dari hasil uji hipotesis (Uji t)} secara parsial antara variabel Pelatihan $\left(X_{1}\right)$ terhadap Produktivitas Kerja Karyawan (Y) diperoleh nilai 0,155 > a 0,05 artinya Ho diterima dan $\mathrm{H}_{\mathrm{a}}$ ditolak maka dapat disimpulkan bahwa secara parsial tidak ada pengaruh yang signifikan antara Pelatihan terhadap Produktivitas Kerja Karyawan pada PT. Tunas Baru Lampung, Tbk-Banyuasin.

Pelatihan Kerja seharusnya dapat berpengaruh Produktivitas Kerja karena selain pengetahuan dan kemampuan yang tinggi karyawan juga membutuhkan Pelatihan yang baik untuk meningkatkan produktivitas kerja.

Hasil ini tidak mendukung penelitian terdahulu yang dilakukan Yesi Triani (2019) yang menyatakan bahwa ada pengaruh yang signifikan antara Pelatihan dan pengembangan SDM terhadap produktivitas kerja.

\section{Pengaruh Pengalaman Kerja Terhadap Produktivitas Kerja Pada PT. Tunas Baru Lampung, Tbk-Banyuasin.}

Selanjutnya hasil pengujian hipotesis (uji t) secara parsial antara variabel Pengalaman Kerja $\left(\mathrm{X}_{2}\right)$ terhadap variabel Produktivitas Kerja (Y) diperoleh nilai $0,000<\alpha \quad 0,05$ artinya $\mathrm{H}_{\mathrm{O}}$ ditolak dan $\mathrm{H}_{\mathrm{a}}$ diterima maka dapat disimpulkan bahwa secara parsial ada pengaruh yang signifikan antara Pengalaman Kerja Terhadap Produktivitas Kerja.

Temuan ini mendukung penelitian terdahulu yang dilakukan oleh Arie Vianti antara Pengalaman Kerja (2019) yang menyatakan bahwa ada pengaruh signifikan pengaruh Pengalaman Kerja dan Jenis Kelamin pada Produktivitas Kerja

\section{Pengaruh Pelatihan dan \\ Pengalaman Kerja Terhadap Produktivitas Kerja Terhadap}

Berdasarkan uji $F$ diperoleh nilai signifikan antara Pelatihan $\left(X_{1}\right)$ dan Pengalaman Kerja $\left(X_{2}\right)$ terhadap Produktivitas Kerja ( $Y$ ) diperoleh nilai Signifikan sebesar $0,000<0,05$, artinya maka hipotesis alternative $\left(\mathrm{H}_{0}\right)$ ditolak dan $\left(\mathrm{H}_{\mathrm{a}}\right)$ diterima, maka dapat disimpulkan bahwa secara bersamasama terdapat pengaruh signifikan antara variabel Pelatihan dan Pengalaman Kerja terhadap Produktivitas Kerja pada PT. Tunas Baru Lampung, Tbk-Banyuasin.

\section{F. KESIMPULAN DAN SARAN \\ 1. KESIMPULAN}

Berdasarkan analisis data dan penjabaran yang telah dilakukan maka dalam penelitian ini dapat diperoleh kesimpulan sebaagai berikut: 
a) Dari hasil pengujian hipotesis (Uji t) secara parsial antara Variabel Pelatihan $\left(X_{1}\right)$ terhadap variabel Produktivitas Kerja $(Y)$ diperoleh nilai signifikan sebesar $0,155>\alpha$ 0,05 maka dapat disimpulkan bahwa secara parsial tidak ada pengaruh yang signifikan antara Pelatihan terhadap Produktivitas Kerja pada PT. Tunas Baru Lampung, Tbk-Banyuasin.

b) Selanjutnya hasil pengujian hipotesis (uji t) secara parsial antara variabel Pengalaman Kerja $\left(X_{2}\right)$ terhadap variabel Produktivitas Kerja $(Y)$ diperoleh nilai $0,000<0,05$ maka dapat disimpulkan bahwa secara parsial ada pengaruh yang signifikan antara Pengalaman Kerja terhadap Produktivitas Kerja pada PT. Tunas Baru Lampung, Tbk-Banyuasin.

c) Dari hasil hipotesis (Uji F) secara bersama-sama antara variabel Pelatihan $\left(\mathrm{X}_{1}\right)$ dan Variabel Pengalaman Kerja $\left(X_{2}\right)$ terhadap Produktivitas Kerja ( $Y$ ) diperoleh nilai signifikan sebesar $0,000<\alpha$ 0,05 maka hipotesis alternative $\left(\mathrm{H}_{\mathrm{a}}\right)$ diterima dan hipotesis nol $\left(\mathrm{H}_{\mathrm{O}}\right)$ ditolak. Maka dapat disimpulkan bahwa secara bersama-sama ada pengaruh yang signifikan antara Pelatihan dan Pengalaman Kerja terhadap Produktivitas Kerja pada PT. Tunas Baru Lampung, TbkBanyuasin.

\section{SARAN}

Beberapa saran yang ingin penulis sampaikan kepada pihak PT. Tunas Baru Lampung, TbkBanyuasiasin adalah sebagai berikut:

a) Diharapkan PT. Tunas Baru Lampung, Tbk-Banyuasin hendaknya melakukan evaluasi yang lebih luas terhadap hasil dan proses Pelatihan yang dilaksanakan, sehingga karyawan lebih menguasai dan memahami materi Pelatihan yang diberikan dengan demikian dapat meningkatkan Produktivitas kerja.

b) Diharapkan instansi yang ada pada PT. Tunas Baru Lampung, Tbk-Banyuasin untuk pimpinanya mengadakan dialog terbuka kepada karyawannya agar bisa saling berbagi pengalaman kerja.

c) Diharapkan hasil penelitian ini dapat menjadi masukan untuk penelitian ditempat lain yang memiliki keragaman SDM yang lebih kompleks dengan mengganti atau menambahkan variabel lain yang dapat dikaitkan dengan komitmen Produktivitas kerja dengan demikian diharapkan dapat mengungkap temuan-temuan penelitian yang lebih menarik dan bermanfaat bagi banyak pihak.

\section{DAFTAR PUSTAKA}

Hasibuan, Malayu 2017. Manajemen Sumber Daya Manusia. Jakarta : PT. Bumi Askara.

Mangkunegara, Anwar Prabu. 2016. Perencanaan dan Pengembangan Sumber Daya Manusia. Bandung : PT. Refika Aditama

Suwatno.Yuniarsih. (2016). Manajemen Sumber Daya Manusia. Bandung: ALFABETA. 